\title{
Dismal obs/gynae training contributing to maternal deaths - Motsoaledi
}

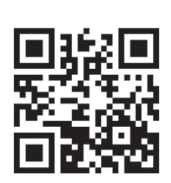

The local standard of training in obstetrics and gynaecology has dropped so dramatically that 'an ordinary caesarean section is now like brain surgery for most interns', says national health minister Dr Aaron Motsoaledi. His claim, made at the South African Medical Association (SAMA)'s Millennium Development Goals (MDGs) conference in Durban at the end of August, was bolstered by one of the world's top maternal mortality researchers, Prof. Jack Moodley, Chairperson of the National Committee on Confidential Enquiries into Maternal Deaths in South Africa (SA) and editor of ten local 'Saving Mothers' reports.

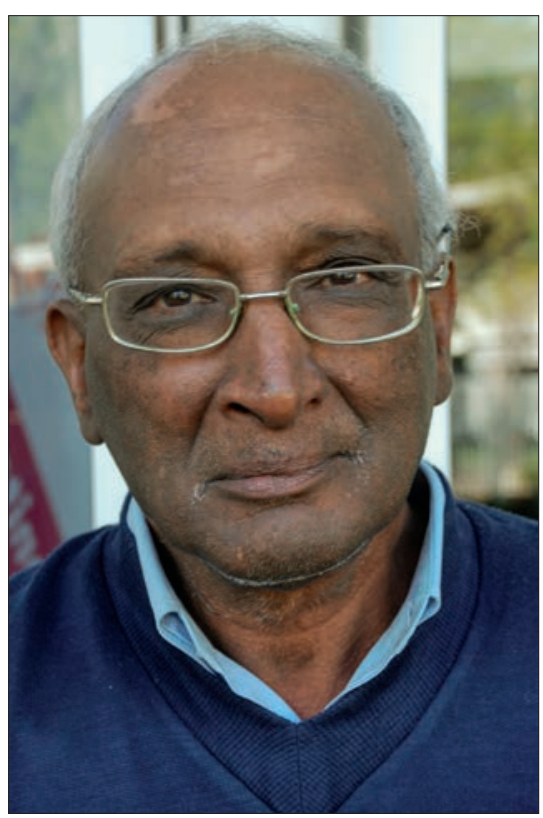

World authority on maternal health, Emeritus Professor Jagidesa ('Jack') Moodley. Picture: Chris Bateman.

Moodley, the SA doyen of hypertensive disorders during pregnancy, told delegates that the latest (yet to be released) maternal mortality data show a worrying new trend - a spike in the number of mothers dying in consultant-served regional hospitals v. district hospitals (where this would be more predictable). 'I don't know whether it's a function of RWOPS-induced lack of consultants or just the paucity of consultants, or a combination of both', he added (RWOPS stands for remunerative work outside the public sector). He said that an increase in caesarean section (CS) deaths was a worrying trend, and urged the newly appointed district clinical specialists to 'take a more handson role in training people'. Clinical heads of academic units should also urgently ensure that interns and medical officers were better versed in performing CSs: 'in fact we'll insist that specialists take an intern through a C-section [in future]. If you ask any specialist if they've trained an intern, the answer usually is "I'm too busy". I'm not sure if they're too busy in limited private practice (RWOPS),' he added. Top medical academics consulted by Izindaba said that neither a community service officer nor a medical officer should be required to perform a CS in the public sector unless fully equipped and trained. 'Otherwise you're just asking for trouble,' said one.

\section{RWOPS controversy flares up again}

The mere linkage of RWOPS to possible increased maternal deaths in regional hospitals - while the country's horrific overall maternal death rate declines at a pace that will fall way short of the MDG target by the end of next year - is akin to pouring petrol on the coals of a long-simmering controversy in the medical profession. Motsoaledi firmly believes that the increase in maternal deaths at regional hospitals is at least partly due to consultants often not being available to train and supervise interns, junior doctors and registrars in crowded public sector maternity wards - because they're too busy in private practice doing RWOPS. He told the SAMA doctors that he had decided he would have to speak urgently with the deans of medical schools, especially in the fields of obstetrics, gynaecology and anaesthetics, and promised to release a report within the next two months. 'Unless we deal with these issues, we'll lose the battle all over again, he added.

Moodley confided to Izindaba after his presentation that what aggravated the unavailability of doctors in the public sector (but perhaps improved the junior learning curve) was the practice of consultants taking juniors with them to conduct RWOPS. ${ }^{[1]}$ The minister and his chief maternal deaths advisor are arguably the most pivotal medical professionals in the much-needed acceleration in saving pregnant women's lives. Motsoaledi said last year that RWOPS was costing lives ${ }^{[2]}-$ but this is the first time any of his confidential enquiry committee's unreleased data have been linked to his claims. Asked for his 'diagnosis' of the decline in healthcare worker training standards as he left the conference, he shot back: 'One word: RWOPS!'

\section{Medical schools deans still pondering RWOPS}

Motsoaledi is currently awaiting comprehensive recommendations from the Committee of Deans of Medical Schools on how to prevent abuse of the RWOPS system after the issue ruptured into the public domain half way through last year - with some provincial health MECs mounting near witch-hunts, accompanied by specialist resignations, official threats and nearslanderous accusations on both sides. ${ }^{[2,3]} \mathrm{A}$ cloud still hangs over scores of consultants under investigation in various provinces, with several senior provincial officials and health politicians stubbornly resisting any suggestion of 'wiping the slate clean' in return for an undertaking by the profession to act promptly and decisively against future offenders.

\section{He criticised the private sector for its predominant lack of maternal mortality and morbidity review meetings or auditing systems.}

The biggest change to the easily and widely abused current set-up will probably be a standardised protocol across provinces with line managers being held directly responsible for ensuring consultants work their minimum 56 hours per week (40 hours plus 16 hours of paid overtime). Motsoaledi, if satisfied, is expected to table such amendments in parliament as a white paper for final enactment, a process that could take 2 years or more. Not only is RWOPS (as practised by some) causing dissension and fall-out among doctors themselves and costing the state hundreds of millions of rands in, for example, botched CSs and adverse birth-related events, but some line managers are reluctant to confront longserving senior colleagues, effectively 'turning a blind eye' and resulting in abusive RWOPS practice becoming close to the norm in several regional and tertiary hospitals. ${ }^{[4]}$ The system was introduced 14 years ago in an effort to 
recruit and retain clinical skills in the public health sector, especially among the more senior specialists who were not earning good salaries at the time. However, this changed in 2009 when the government reviewed salary packages, introducing the controversial Occupation-Specific Dispensation (OSD), which significantly bumped up the incomes of the most junior and the more senior doctors. The latest salary scales, updated in April last year, show that a newly qualified specialist will earn R747 674 per annum plus R200 000 per annum for 16 hours of commuted overtime each week. After 5 years the annual salary will be around R854 751 plus R200 000 overtime. This has lent weight to accusations that absences from public sector consultancy posts (where up to $80 \%$ of the population is served) are motivated by financial greed.

\section{'We came out of the starting blocks late' - Motsoaledi}

Motsoaledi expressed regret at his department's having only followed the recommendations of the three ministerial committees (confidential enquiries into the commonest causes of maternal, perinatal and under- 5 deaths, set up in 2002) in 2009. 'We came very late out of the starting blocks', he admitted. Moodley and his fellow researchers found that HIV/AIDS, obstetric haemorrhage and hypertension are the three main causes of maternal deaths. A full $40 \%$ of all maternal deaths are due to HIV, making screening of all HIV-positive pregnant women for pneumonia and tuberculosis a top priority. Obstetric hemorrhage, while highly preventable, was 'a battle we can't seem to win'. Moodley singled out deaths due to haemorrhage associated with CSs, saying this 'might imply' that too many CSs were being done (an overall rate of $25 \%$ in the public sector and $65 \%$ in the private sector). What he said he was certain about was that more complications were likely with CSs. In the public sector his teams' research showed the procedure to be associated with poor surgical technique: 'so we're not training our doctors well to do CSs', he stressed. Decisions about when to do the procedure were probably made too late, resulting in death or disability for the mother and/or infant, he added. SA's private sector should have a maternal mortality rate similar to that in the UK $(8.2 / 100000$ women), 'as our equipment and resources here are as good, if not better. However, the local private sector maternal mortality rate stood at about 40/100 000 women. He criticised the private sector for its lack of maternal mortality and morbidity review meetings or auditing systems. 'T've been going around cajoling them to report all maternal deaths and giving them

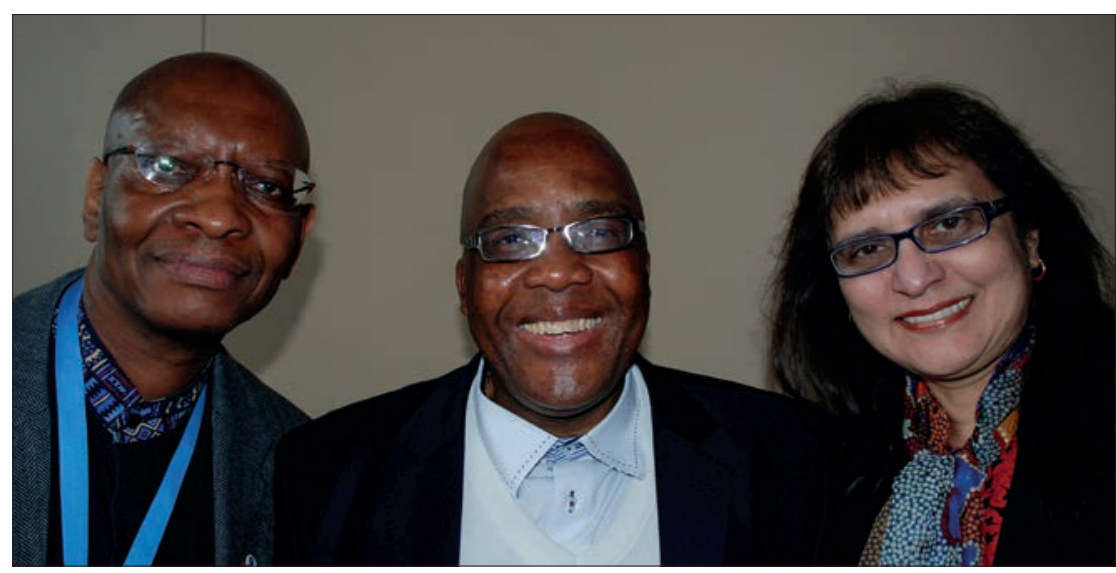

SAMA Chairperson Dr Mzukisi Grootboom, Health Minister Dr Aaron Motsoaledi and SAMA President Prof. Ames Dhai. Picture: Chris Bateman.

reasons why we want to record, he added. His experience from these visits was that doctors did not attend peer review meetings.

\section{Asked for his 'diagnosis' of the decline in healthcare worker training standards as he left the conference, national health minister, Dr Aaron Motsoaledi shot back 'One word: RWOPS!'}

Moodley appealed to SAMA to ask itself how it could get private doctors to attend such meetings and learn from their faults and to urge doctors to attend the Essential Steps Management of Obstetric Emergencies (ESMOE) course, plus encourage the team training of doctors and nurses. Combined, these measures had the potential to reduce maternal deaths dramatically. Moodley said the entire point of his talk was to explore how his audience and the healthcare profession in general could help reduce maternal deaths 'without apportioning blame and dishing out punishment'.

\section{Maternal deaths highly preventable}

'We're here to learn, and hopefully minimise future maternal deaths', he said, stressing that in $60 \%$ of these deaths there was an avoidable factor - with this figure in anaesthetics and obstetric haemorrhage standing at $90 \%$ and $80 \%$, respectively. Moodley warned against the high risk of 'single-operator CSs' in district hospitals, where many GPs conducted spinal blocks. The argument is often made that the critical shortage of doctors (and anaesthetists) means this is virtually unavoidable. Moodley's answer is to reassign CSs to centralised hospitals. 'There are some hospitals that do so few CSs that they shouldn't be doing them at all', he warned. Motsoaledi said that although Moodley's committee had made 'the three Hs famous', he had another two to add. These were healthcare worker training and health system strengthening.

The maternal mortality MDG goal is to reduce the maternal mortality ratio by threequarters between 1990 and 2015. Maternal deaths per 100000 live births in SA stood at 150 in 1998, climbing to a peak of 312 in 2009 before dropping to 269 in late 2010 - as the findings of Moodley's team began to be acted upon. SA's MDG target for next year is 38 , which Motosaoledi describes as 'a possible or impossible dream'

Prof. Ames Dhai, SAMA President and Head of the Steve Biko Centre for Bioethics at the University of the Witwatersrand, said that Moodley's presentation showed either a 'lack of care or negligence' among doctors. 'We don't have sufficient role models in our academic institutions to ensure professionalism and we concentrate too much on the clinical aspects', she added. SAMA chairman Dr Mzukisi Grootboom said that the drop in training standards was a 'serious challenge' which SAMA would be taking up to ensure that those who come after us are educated to make the profession relevant'.

\section{Chris Bateman \\ chrisb@hmpg.co.za}

S Afr Med J 2014;104(10):656-657.

DOI:10.7196/SAMJ.8905

$$
\begin{aligned}
& \text { 1. Bateman C. RWOPS abuse 'eroding ethical standards of juniors'. } \\
& \text { S Afr Med J 2013;103(8):505-506. [http://dx.doi.org/10.7196/ } \\
& \text { SAMJ.7165] } \\
& \text { 2. Bateman C. RWOPS abuse - Government's had enough. S } \\
& \text { Afr Med J 2012;102(12):899-901. [http://dx.doi.org/10.7196/ } \\
& \text { SAMJ.6481] } \\
& \text { 3. Bateman C. RWOPS clampdown - a crisis in the offing. S } \\
& \text { Afr Med J 2013;103(6):361-364. [http://dx.doi.org/10.7196/ } \\
& \text { SAMJ.7029] } \\
& \text { 4. Bateman C. RWOPS - light at the end of a dusty tunnel. S Afr } \\
& \text { Med J 2013;103(12):888. [http://dx.doi.org/10.7196/SAMJ.7693] }
\end{aligned}
$$

